\title{
PERANCANGAN SISTEM DATA WAREHOUSE PEMBELAJARAN PADA PONDOK PESANTREN AL-FURQON
}

\author{
Padeli $^{1}$ \\ Muhammad Dzulfikar Allam² \\ Nurviani Riska Suharto ${ }^{3}$ \\ Dosen STMIK Raharja Tangerang ${ }^{1}$, Mahasiswa STMIK Raharja Tangerang ${ }^{2,3}$ \\ J1 Jenderal Sudirman no.40, Modern, Cikokol Tangerang $1,2,3$ \\ Email :padeli@ raharja.info ${ }^{1}$, dzulfikarallam@ raharja.info ${ }^{2}$, nurviani.riska@ raharja.info
}

\begin{abstract}
ABSTRAK
Yayasan Al-furqon merupakan yayasan kelembagaan pendidikan berbasis agama yang biasa di sebut pondok pesantren. Dengan bertambahnya peserta didik pada pesantren Al-furqon dan juga bertambahnya staff pendidik yang akan ikut andil dalam kegiatan mengajar dan belajar. Berarti semakin bertambah pula informasi, informasi yang bertambah tersebut membutuhkan proses pengolahan dan analisis sebelum di simpan untuk keperluan pesantren. Untuk selanjutnya di buatkan laporan dan disampaikan kepada Departemen Agama yang membidangi Pondok Pesantren. Masalah yang ada saat ini adalah semakin bertambahnya waktu untuk melakukan proses pengolahan informasi yang tersimpan dalam database menjadi laporan. Maka diperlukan sebuah system atau aplikasi yang dapat melakukan penyimpanan big data dan mengolah informasi, melakukan analisis dan melaporkan hasil analisis data. Metode yang di lakukan adalah dengan menghimpun sumber data yang dibutuhkan melalui observasi dan wawancara untuk kemudian dilakukan analisa dengan metode SWOT, di mana dengan metode ini di jelaskan kekurangan, kelebihan dan peluang perbaikan pada suatu sistem. Dengan melakukan penelitian pada pesantren Al-furqon, di harapkan dapat menghasilkan sebuah data warehouse untuk yayasan serta dapat menganalisa jumlah kapasitas media penyimpanan yang dibutuhkan untuk data histori.
\end{abstract}

Kata Kunci: Data Base, Data Warehouse.

\section{ABSTRACT}

Al-furqon is foundation of faith-based education that is commonly called the boarding school. Along with the increasing number of students each year the more the teacher or teachers who will take part in the activities of teaching and learning. Thus the more the data that goes into the institution or Pondok Pesantren Al-furqon, these data would need to be stored, processed, and analyzed to produce a useful information for the institution, and reported to the Ministry of Religious Affairs in charge of boarding school. Meanwhile, to make the report, it takes more time to collect information and process data stored in operational databases in the institution. Since it is considered necessary to manage large amounts of data in order to produce an information quickly, then made a design of the data warehouse to facilitate the conduct of data processing, analyzing and reporting the data analysis. The method used the data collection methods, such as observation, interviews, and literature review. After getting the data and then analyzed with the SWOT method, this method describes the shortcomings, strengths and opportunities for improvement in the system. This research resulted in a data warehouse for Al-furqon institution, as well as the amount of storage capacity needed for historical data.

Key Word : Data Base, Data Warehouse. 


\section{PENDAHULUAN}

Perkembangan sistem belajar mengajar saat ini berkaitan erat dengan perkembangan sistem informasi. Kualitas sistem belajar mengajar dan pengolahan informasi untuk keperluan administrasi pada sekolah pun menjadi bagian yang penting, sehingga dengan bantuan kecanggihan teknologi berupa sebuah aplikasi dalam layanan sebuah informasi. Kecepatan dan efektifitas dalam melakukan pengolahan informasi ini akan dapat meningkatkan efisiensi waktu dan tempat.

Dengan bertambahnya jumlah peserta didik pada pesantren al-furqon maka bertambha juga data yang di record ke dalam database. Dan masalah yang sering dihadapi dalam hal ini adalah dalam melakukan manajemen sumber data. Dalam melakukan seleksi penerimaan santri/siswa di perlukan sumber informasi yang mudah untuk di fahami sehingga lebih cepat dalam pembuatan laporan. Untuk memudahkan dalam melakukan analisis dan penyajian informasi dengan kapasitas besar, dibutuhkan manajemen basis data yang cocok untuk pihak yang berkepentingan. Salah satunya adalah dengan data warehouse yang dapat mendukung perkembangan yayasan kedepannya baik dari segi kuantitas ataupun kualitas. Dengan bertambahnya jumlah peserta didik pada Ponpes Al-furqon, semakin rumit pula data-data yang ada dan harus diolah. Data yang ada cukup menyulitkan pihak ponpes dalam mengolah seluruh data yang ada. Penyajian informasi yang sesuai dengan kebutuhan pihak ponpes alfurqon sering menemui kendala dalam hal kecepatan pelaporan dan keterbatasan akses sumber daya database. Dengan demikian keputusan yang di ambil terkadang menjadi kurang baik. Dalam mengolah data yang berukuran sangat besar sebagai bahan analisis untuk keperluan tertentu di butuhkan sebuah desain system informasi yang efektif dan efisien

Dengan dilakukannya penelitian manajemen data warehouse ini mudah-mudahan mampu menciptakan desain system informasi untuk memonitor aktiftas dari guru/ustadz serta dapat menghasilkan sebuah sistem yang dapat di jadikan sebagai alat bantu dalam proses pembelajaran di pondok pesantren dalam meningkatkan mutu pendidikan.

\section{LANDASAN TEORI}

\section{Data Warehose}

Data warehouse adalah database relasional yang dirancang untuk query dan analisis data dan bukan untuk pemrosesan transaksi. Biasanya berisi data historis yang berasal dari data transaksi dapat juga berasal dari sumber lain. Data warehouse dapat memisahkan analisis beban kerja dari proses transaksi dan memungkinkan organisasi untuk mengkonsolidasikan data dari beberapa sumber. Data warehouse didesain untuk mengakomodasi permintaan data yang besar jika pengguna tidak tahu beban kerja sebuah manajemen database maka data warehouse dapat melakukan operasi yang optimal untuk melakukan berbagai macam operasi query yang mungkin.. Pengukuran validitas juga bisa menggunakan variasi/perbedaan waktu yang disajikan dalam data warehouse baik implicit maupun explicit, secara explicit dengan unsur waktu dalam hari, minggu, bulan dan waktu tertentu atau variasi yang disajikan data warehouse melalui serangkaian snapshoot yang panjang. data warehouse tidak diupdate secara real time tetapi di refresh dari sistem operasional secara reguler. Data yang baru selalu ditambahkan bagi basis data itu sebagai sebuah perubahan. Database yang ada ini akan terus menyimpan record secara terus menerus. Hal ini berbeda dengan basis data konvensional yang menggunakan metode CRUD, data warehouse hanya melakukan dua aktifitas dalam manipulasi data yaitu mengambil data dan akses data. ketika sebuah organisasi memutuskan untuk membangun sebuah data warehouse langkah awalnya adalah dengan mendefinisikan kebutuhan bisnis dan menentukan ruang lingkup aplikasi serta menciptakan desain konseptual, dan selanjutnya menerjemahkan kebutuhan data ke dalam sistem penyimpanan. baru kemudian dibuat desain database untuk baik logis maupun fisik. Sebuah desain logis memuat desain konsep dan abstrak. seorang database administrator tidak berurusan dengan 
rincian pelaksanaan fisik namun hanya bertugas untuk mendefinisikan jenis informasi yang di butuhkan.

Salah satu teknik yang dapat digunakan untuk membuat model kebutuhan informasi logis adalah dengan menggunakan menggunakan pemodelan ERD. pemodelan ini digunakan untuk menentukan entitas, atribut dan bagaimana entitas dan attribut tersebut saling berhubungan satu sama lain melalui konsep relasional.

Skema adalah kumpulan objek database, termasuk tabel, view, indeks, dan sinonim. Anda dapat mengatur objek skema dalam model skema yang dirancang untuk penyimpanan data dalam berbagai cara. Kebanyakan data warehouse menggunakan model dimensi. sumber database yang ada dapat memenuhi persyaratan pengguna dalam membantu merancang skema data warehouse. sumber data ini bisa didapatkan dari model data perusahaan perusahaan. implementasi model fisik dan logis mungkin memerlukan beberapa perubahan untuk disesuaikan dengan parameter sistem anda seperti spesifikasi server, jumlah pengguna, kapasitas penyimpanan, jenis jaringan, dan perangkat lunak.

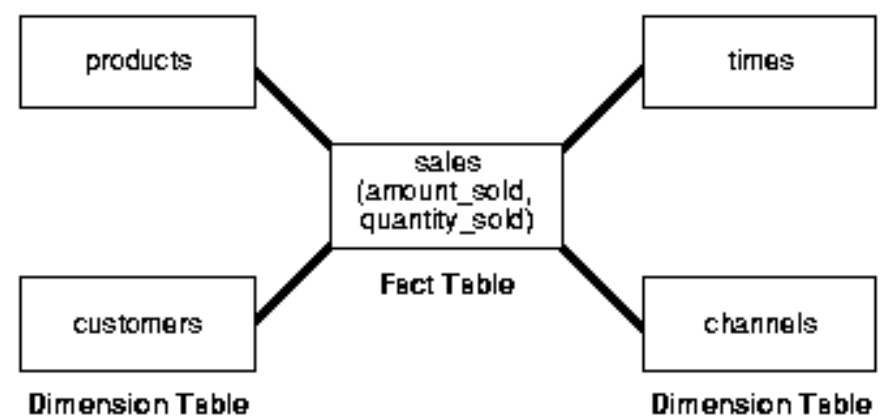

\section{Meotde Penelitian}

Gambar 1. Salah satu skema pada data warehouse

Dalam melakukan penelitian ini digunakan analisa dari internal dan eksternal untuk mendapatkan potensi yang dimiliki dan ancaman yang mungkin muncul sehingga didapatkan kebutuhan sistem untuk menunjang dalam melakukan analisis data yang dimiliki sehingga dapat dijadikan alat bantu bagi keseluruh instrumen pesantren yang membutuhkan data dan informasi kegiatan seputar proses pembelajaran

Table 1. Tabel Analisa SWOT

\begin{tabular}{|c|c|}
\hline Strengths & Weakness \\
\hline $\begin{array}{l}\text { Pondok Pesantren Al-furqon Cilegon memiliki } \\
\text { sistem pondok pesantren yang memadai dari } \\
\text { mulai keamanan, keterjagaan lingkungan, dan } \\
\text { sistem disiplin yang berjalan. } \\
\text { Guru ataupun Pimpinan Pondok Pesantren } \\
\text { tidak membeda-beda kan santri dari golongan } \\
\text { manapun. } \\
\text { Kegiatan pembelajaran di Pondok Pesantren } \\
\text { mengutamakan kegiatan pembelajaran } \\
\text { keagamaan yang menjadi landasan dasar hidup } \\
\text { manusia. }\end{array}$ & $\begin{array}{l}\text { Tidak semua bagian yang ada di pondok } \\
\text { pesantren terkontrol secara komputerisasi. } \\
\text { Seperti kegiatan proses pembelajaran tidak } \\
\text { semuanya sudah tertata rapih } \\
\text { menggunakan sistem pembelajaran, } \\
\text { sehingga data yang di sampaikan ke } \\
\text { pimpinan terkadang masih belum akurat. } \\
\text { Dalam kebanyakan kegiatan di Pondok } \\
\text { Pesantren masih ketergantungan terhadap } \\
\text { sistem yang manual. }\end{array}$ \\
\hline Oportunities & Threats \\
\hline
\end{tabular}




\begin{tabular}{|l|l|}
\hline Data Laporan setiap kegiatan yang & Jika sistem tidak diterapkan maka proses \\
berhubungan dengan proses pembelajaran akan & akan terlalu membutuhkan banyak waktu. \\
bisa dihasilkan dengan cepat dan akurat, & Jika ada keterlambatan maka akan \\
sehingga kegiatan proses pembelajaran dapat & mengganggu kegiatan-kegiatan lain diluar \\
dilakukan evaluasi dengan cepat dan segera & kegiatan proses pembelajaran. \\
dilakukan. & \\
\hline
\end{tabular}

Setelah dilakukan analis SWOT maka di buatlah analisa lanjutan dengan menggunakan matriks yang untuk menjelaskan peluang yang mungkin dapat di ambil oleh organisasi dengan menggunakan kekuatan dan peluang yang dimiliki serta menyelesaikan masalah dengan identifikasi kelemahan dan ancaman sehingga di dapatkan sebuah cara untuk meminimalisir potensi yang dapat menghambat kemajuan organisasi secara keseluruhan.

Tabel 2. Matriks Analsia SWOT

\begin{tabular}{|c|c|c|}
\hline$\underbrace{\text { Internal }}_{\text {Eksternal }}$ & $\begin{array}{l}\text { Strengths } \\
\text { (S) } \\
\text { Kekuatan }\end{array}$ & $\begin{array}{l}\text { Weakness } \\
\text { (W) } \\
\text { Kelemahan }\end{array}$ \\
\hline & SO & WO \\
\hline $\begin{array}{c}\text { Oportunities } \\
\text { (O) } \\
\text { Peluang }\end{array}$ & $\begin{array}{l}\text { Mengembangkan dan } \\
\text { merancang sebuah sistem data } \\
\text { yang memudahkan admin } \\
\text { pendataan untuk pengolahan } \\
\text { data dalam memberikan laporan } \\
\text { maupun informasi bagi } \\
\text { pimpinan atau kepada santri }\end{array}$ & $\begin{array}{l}\text { Meningkatkan kualitas } \\
\text { pelayanan khususnya untuk } \\
\text { admin data sehingga guru dan } \\
\text { santri dapat mengikuti } \\
\text { kegiatan pembelajaran dengan } \\
\text { tepat waktu. }\end{array}$ \\
\hline & ST & WT \\
\hline $\begin{array}{c}\text { Threats } \\
\text { (T) } \\
\text { Ancaman }\end{array}$ & $\begin{array}{l}\text { Merancang sebuah sistem yang } \\
\text { dibangun agar dapat membuat } \\
\text { pekerjaan admin data dapat } \\
\text { diolah dan dikerjakan secara } \\
\text { cepat dan akurat. }\end{array}$ & $\begin{array}{l}\text { Melakukan pembaharuan data } \\
\text { dan informasi dengan cepat } \\
\text { sehingga informasi yang } \\
\text { disampaikan akan cepat } \\
\text { diterima oleh pimpinan, guru, } \\
\text { dan santri. }\end{array}$ \\
\hline
\end{tabular}

Penelitian tentang data warehouse telah banyak dilakukan sebelumnya, misalnya penelitian yang dilakukan oleh Iik Wilarso pada tahun 2012. Pada penelitian ini penulis membahas mengenai pemanfaatan teknologi data warehouse pada institusi pendidikan tinggi di di Indonesia digunakan Universitas Indonesia (UI) sebagai studi kasus dan sebagai pembanding adalah Florida State University yang telah membangun dan memanfaaatkan data warehouse yang relative cukup lengkap. Setelah diteliti institusi pendidikan tinggi Indonesia jauh tertinggal dengan institusi pendidikan tinggi di beberapa Negara maju seperti Amerika. Penelitian yang lain adalah Penelitian yang dilakukan oleh Rian Pratama, Suci Roisyah, dan Abdul Rahman pada tahun 2013 yang melakukan penelitian pada perancangan Data Warehouse pada disdikpora kota Palembang dengan menggunakan metodologi Sembilan tahap. Yaitu : pemilihan proses, pemulihan Grain, identifikasi dan penyesuaian dimensi, pemilihan fakta, penyimpanan pre calculation di tabel fakta, memastikan table pada dimensi yang ada, memilih waktu pemakaian database, mengetahui database yang berubah secara perlahan, menentukan skala prioritas dan permodelan untuk bahasa query. Dengan demikian pihak disdikpora dapat lebih mudah memantau dan melakukan analisa dalam peningkatan 
jumlah peserta didik dari berbagai dimensi seperti : tingkat kelas, , dan nilai rata-rata, jenis kelamin, kelurahan, umur, agama dan, kecamatan.

\section{HASIL DAN PEMBAHASAN}

Setelah dilakukan analisa dengan menggunakan metode yang ada maka di dapat kesimpulan bahwa pengolahan data santri pada Pondok Pesantren Al-furqon Cilegon masih terdapat beberapa masalah diantaranya :

1. Pada Bagian kegiatan pembelajaran harus memproses data-santri dan data nilai sebagai acuan penilaian kegiatan pembelajaran.

a) Data santri yang ada saat ini dalam proses pembelajaran masih terjadi double atau terjadi kesalahan penginputan.

b) Data Nilai saat ini masih menggunakan metode manual yang memungkinkan terjadinya kesalahan penilaian terhadap hasil dari ujian santri.

c) Lama dan seringnya terjadi kesalahan data pada laporan dan informasi pada kegiatan pembelajaran maka proses pengolahan data perlu dilakukan agar tidak terjadi kembali proses yang lamban dan kesalahan pada data dan informasi.

Dari beberapa permasalahan yang sudah di sebutkan di atas, maka perlu dibuatkan sebuah desain system informasi yang dapat dengan efektif melakukan pengolahan data atau informasi dan menyajikannya dalam bentuk yang lebih mudah untuk di fahami. Beberapa alternative pemecahan masalah yang lain diantaranya :

1. Membuat sebuah desain database untuk mengolah data santri pada bagian khususnya bidang pengajaran. Dimana bagian pengajaran bertanggung jawab atas terjadinya proses kegiatan KBM. Agar tidak terjadinya keterlambatan dan kesalahan data pada bagian pengajaran, dengan demikian akan mempermudah cara pendataan yang akan ditampilkan ke santri dan di laporkan ke Pimpinan.

2. Membangun sebuah sistem yang dapat melakukan analisis data secara efektif dan efisien dan dapat memberikan kemudahan bagi guru, santri dan stake holder sehingga proses kegiatan belajar mengajar dapat berjalan dengan baik.

Untuk memperbaiki dan menyempurnakan system yang berjalan saat ini dapat di buat beberapa prosedur, diantaranya adalah dengan memonitoring kegiatan belajar mengajar melalui data update dilakukan oleh super admin, admin, guru, santri dan Admin TU. Setelah kebutuhan-kebutuhan di tentukan maka selanjutnya adalah membuat desain system informasi yang dapat memebuhi kebutuhan setiap pengguna. Yaitu dengan menyusun prosedur system usulan, membuat desain database dan selanjutnya merancang tampilan antar muka.

\section{Prosedur Sistem Yang Diusulkan}

Pengolahan data dengan system yang diusulkan ini dilakukan oleh tiga hak akses. Diantaranya admin yang dapat mengakses seluruh menu yang ada, hak akses ini di miliki oleh admin dan TU sedanggkan user hanya dapat melihat data master dan tidak dapat melakukan pengolahan data-data yang ada. Keseluruhan system yang disusulkan dapat digambarkan dalam diagram berikut : 


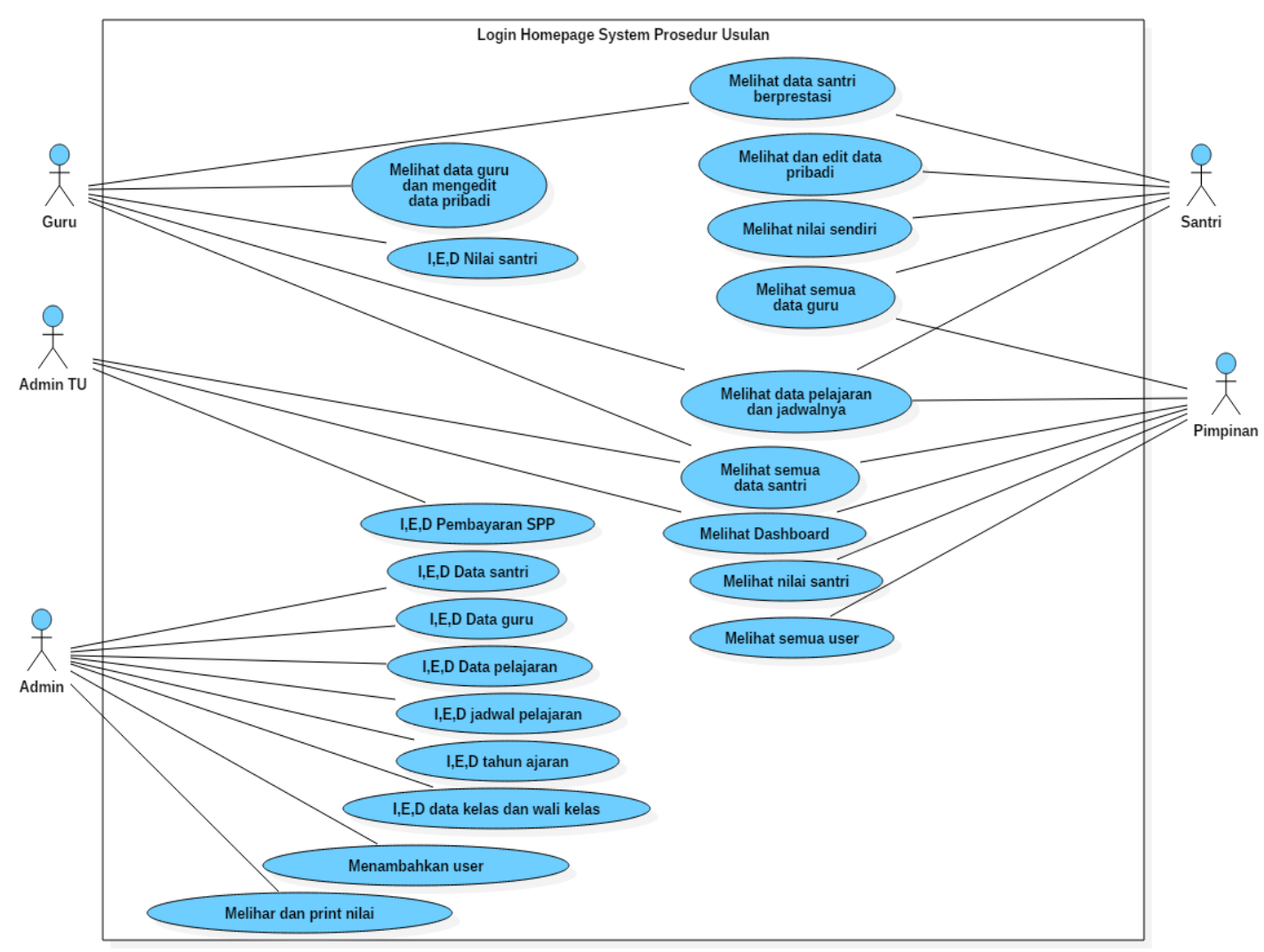

\section{Rancangan Basis Data}

\section{Gambar 2. Diagram,system yang diusulkan}

desain database adalah penjabaran struktur pada database untuk merencanakan, menyimpan dan mengolah data. konsistensi data dicapai ketika database dirancang untuk menyimpan data sesuai dengan kebutuhan. Salah satunya adalah dengan menentukan kunci utama dan batasannya untuk memastikan konsistensi data yang disimpan. penentuan kunci.utama juga digunakan untuk keseragaman data. desain database yang baik sangat penting dalam memastikan data yang konsisten, mengurangi redundansi data, meningkatkan efisien dari query yang berjalan sehingga aplikasi berjalan dengan kinerja tinggi. merancang database yangg baik dapat menghemat waktu dan mengurangi kendala selama 
pengembanganserta menjamin kemudahan akses dan pengambilan informasi.

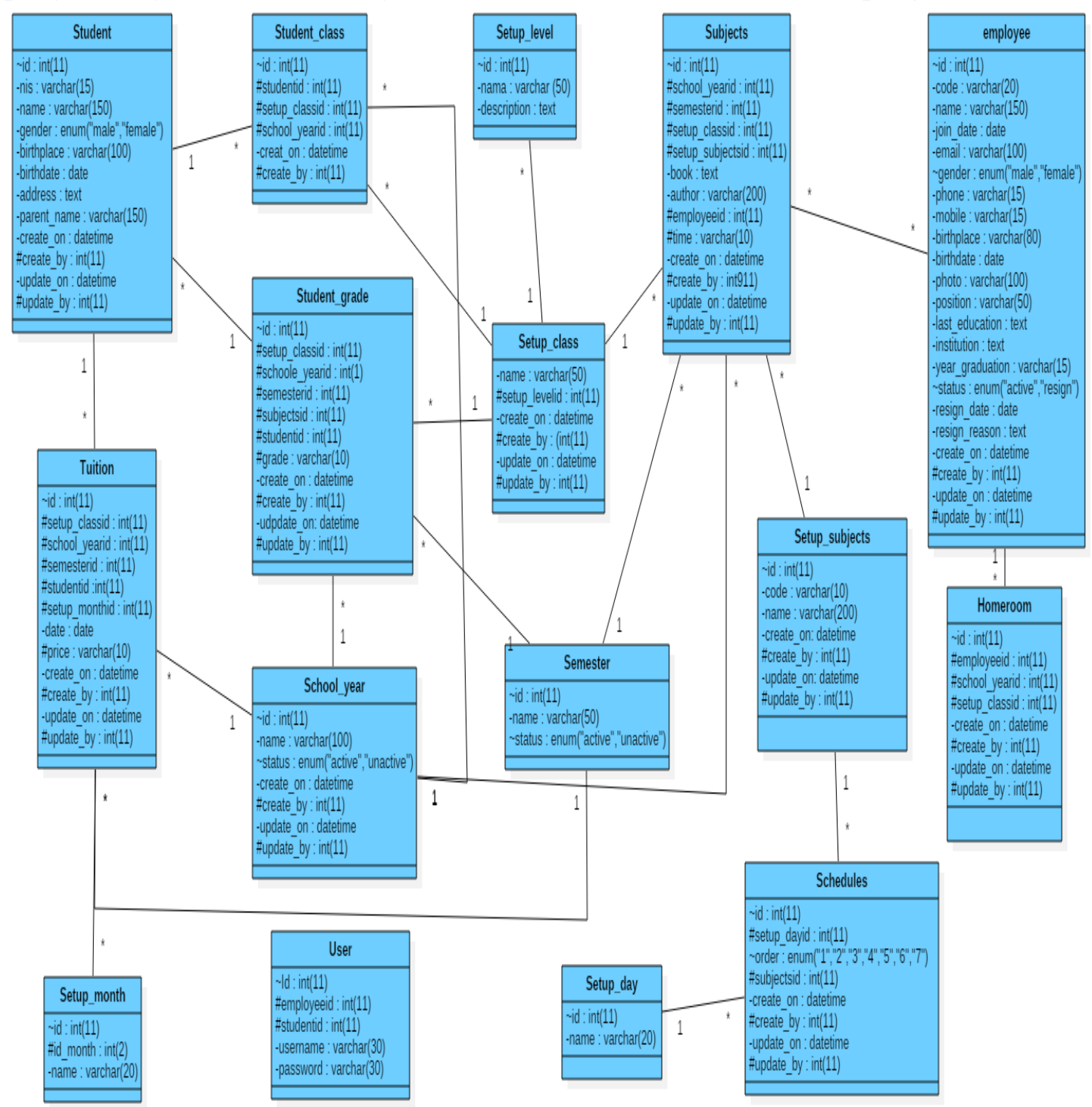

Gambar 3. Class diagram yang diusulkan

Pengujian pada system ini dilakukan dengan menggunakan Black Box Testing. Yang juga dikenal sebagai fungsional testing, sebuah teknik yang melakukan pengujian perangkat lunak dimana kerja internal dari item yang diuji tidak diketahui oleh tester. Misalnya, dalam melakukan pengujian pada perangkat lunak dimana desain tester hanya tahu input dan apa hasil yang diharapkan dan tidak harus mengetahui bagaimana program dapat meghasilkan output. Tester tidak pernah memeriksa kode program dan tidak memerlukan pengetahuan lebih lanjut tentang bahasa programan

Hasil rancangan aplikasi yang dibuat dapat dilihat pada gambar berikut :

Halaman login 


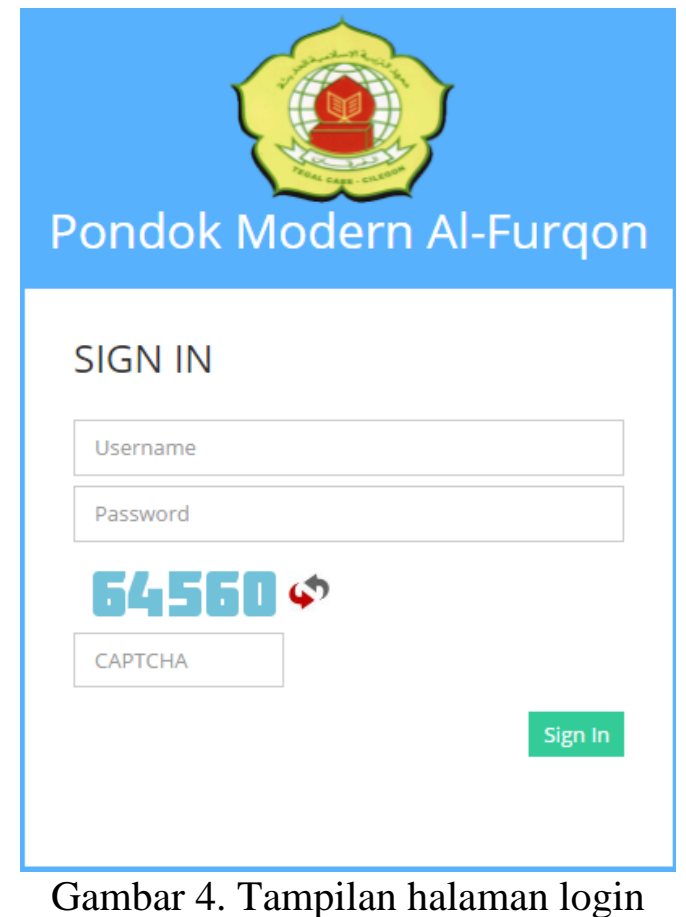

\section{Tampilan Layar Menu Dashboard}

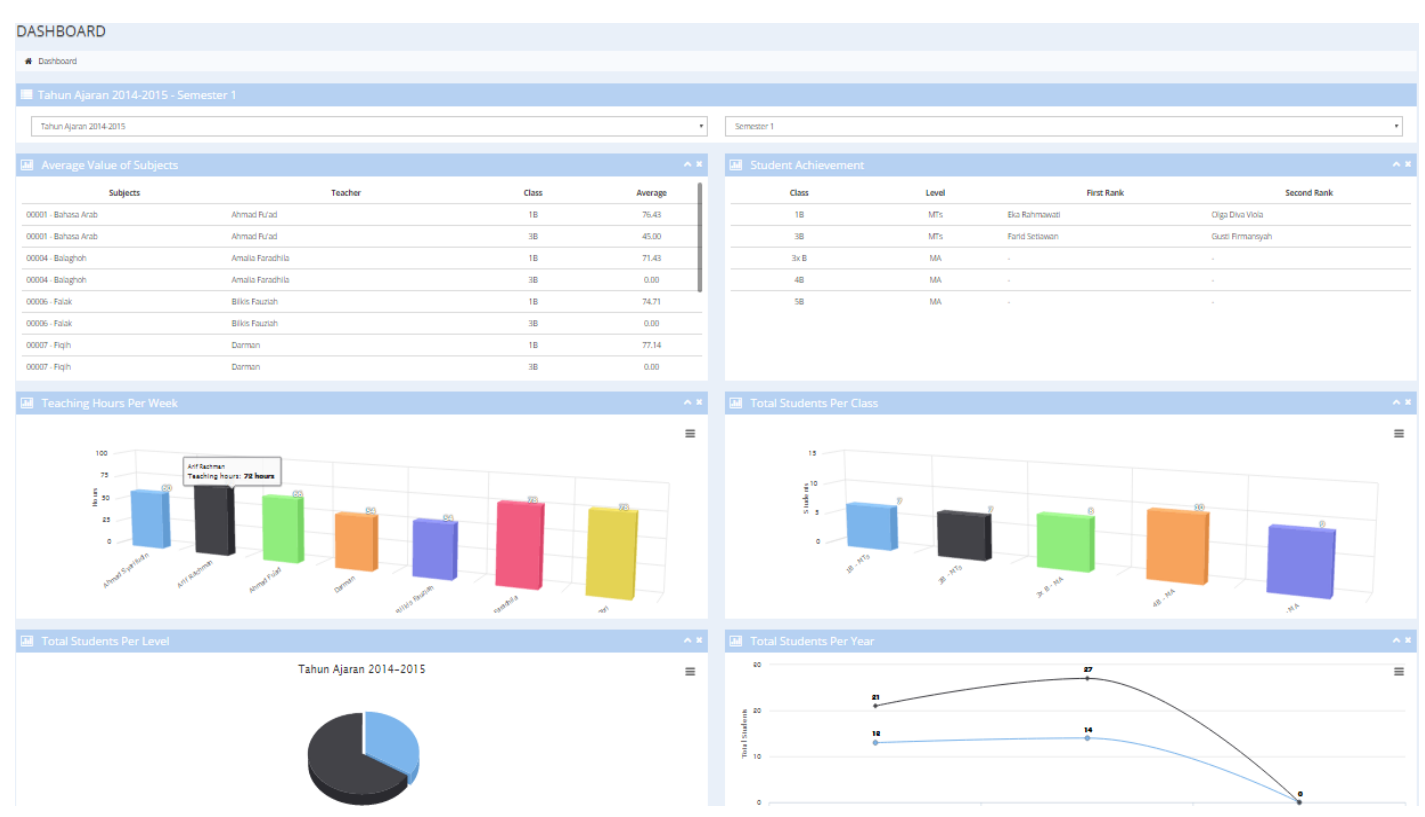

Gambar 5 Tampilan Halaman Dashboard 


\section{Tampilan Layar Menu Employee}

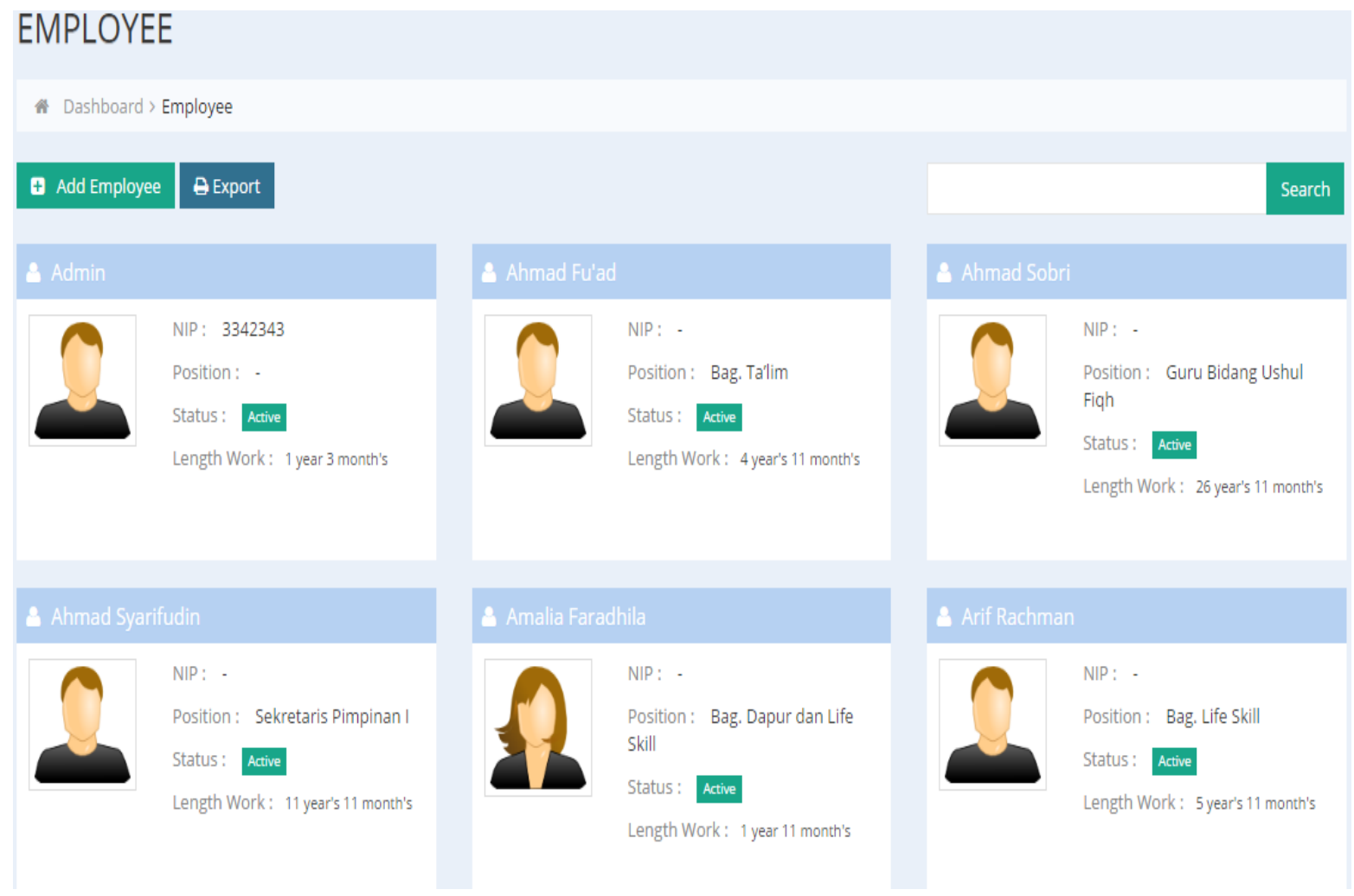

Gambar 6 Tampilan Halaman Employee

\section{Tampilan Layar Menu Student}

\begin{tabular}{|c|c|c|c|c|c|c|c|c|}
\hline \multicolumn{9}{|c|}{ * Dashboard > Student } \\
\hline$\uplus$ Add Student & E Export & & & & & & & \\
\hline \multicolumn{9}{|c|}{ E Data Student } \\
\hline \multicolumn{2}{|c|}{$10 \quad$ Records per page } & & & & \multicolumn{4}{|c|}{ Search: } \\
\hline NIS & Name & 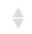 & Gender & Birthplace & $\hat{y}$ & Birthdate $A$ & Parent & $\Leftrightarrow$ Action \\
\hline 1213.1.131 & Anton Mustakmal & & Male & Waykalam & & 09/03/1996 & Solihin & \\
\hline 1213.1 .132 & Anisa Ruhadini & & Female & Cilegon & & $12 / 10 / 1996$ & Mustaqim A & \\
\hline 1213.1 .133 & Siti Khoeriyah & & Female & Cilegon & & $10 / 12 / 1997$ & Mad Salim & \\
\hline 1213.1 .134 & Sri Wulandari & & Female & Kalianda & & $17 / 02 / 1997$ & Sonhaji & \\
\hline 1213.1 .135 & Sifaurrohmah & & Female & Kampung Baru & & $01 / 01 / 1970$ & Muhaimin & \\
\hline 1213.1 .136 & M. Tubyani & & Male & Cilegon & & $22 / 06 / 1996$ & Badri & \\
\hline 1213.1.137 & Topan Muldiana & & Male & Suka Bumi & & $01 / 01 / 1970$ & Eman & \\
\hline
\end{tabular}

Gambar 7 Tampilan Halaman Student 


\section{Pengujian Black Box Pada Login}

Dibawah ini adalah hasil pengujian dari system yang dibuat dengan menggunakan blackbox testing. Item yang diuji di buat dengan scenario yang telah ditentukan untuk selanjutnya di lakukan pengujian dan di catat hasil pengujian yang telah di lakukan:

Tabel 4. Tabel Pengujian Black box Pada Login

\begin{tabular}{|c|c|c|c|c|c|}
\hline No & Skenario Pengujian & Test Case & $\begin{array}{l}\text { Hasil yang } \\
\text { diharapkan }\end{array}$ & Hasil Pengujian & $\begin{array}{c}\text { Kesimpul } \\
\text { an }\end{array}$ \\
\hline 1 & $\begin{array}{c}\text { Mengosongkan username } \\
\text { password dan captcha, lalu } \\
\text { langsung klik tombol "sign } \\
\text { in". }\end{array}$ & 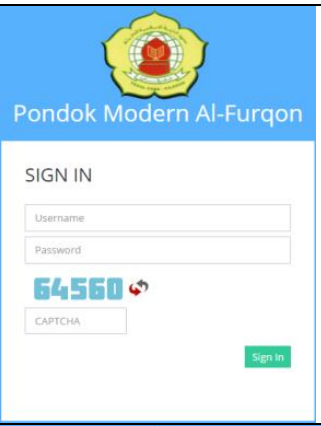 & $\begin{array}{l}\text { Sistem akan } \\
\text { menolak akses } \\
\text { sign in dan } \\
\text { menampilkan } \\
\text { pesan } \\
\text { "username, } \\
\text { password dan } \\
\text { capthca tidak } \\
\text { boleh } \\
\text { kosong". }\end{array}$ & 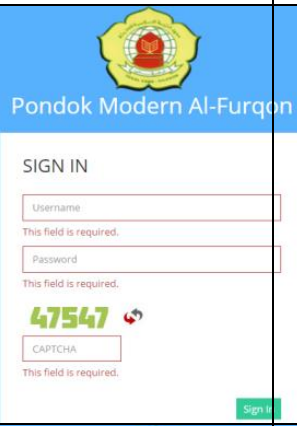 & Valid \\
\hline 2 & $\begin{array}{l}\text { Hanya mengisi username, } \\
\text { captcha dan } \\
\text { mengosongkan password, } \\
\text { lalu langsung klik tombol } \\
\text { "sign in". }\end{array}$ & 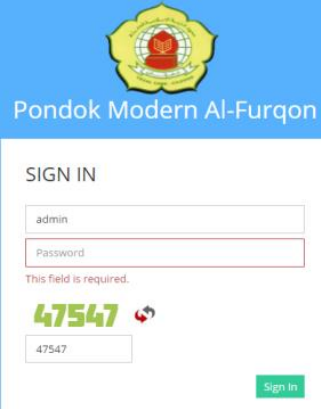 & $\begin{array}{l}\text { Sistem akan } \\
\text { menolak akses } \\
\text { sign in dan } \\
\text { menampilkan } \\
\text { pesan } \\
\text { "password } \\
\text { tidak boleh } \\
\text { kosong". }\end{array}$ & 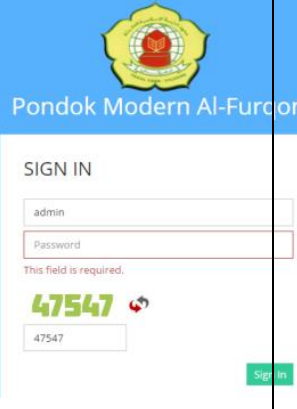 & Valid \\
\hline 3 & $\begin{array}{l}\text { Hanya mengisi password, } \\
\text { captcha dan } \\
\text { mengosongkan username, } \\
\text { lalu langsung klik tombol } \\
\text { "sign in". }\end{array}$ & 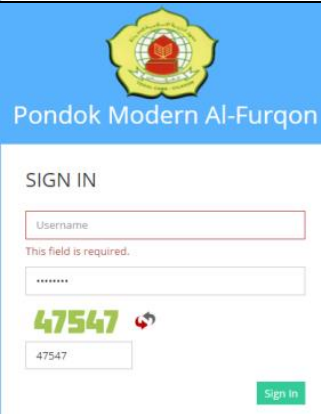 & $\begin{array}{l}\text { Sistem akan } \\
\text { menolak akses } \\
\text { sign in dan } \\
\text { menampilkan } \\
\text { pesan } \\
\text { "username, } \\
\text { tidak boleh } \\
\text { kosong". }\end{array}$ & 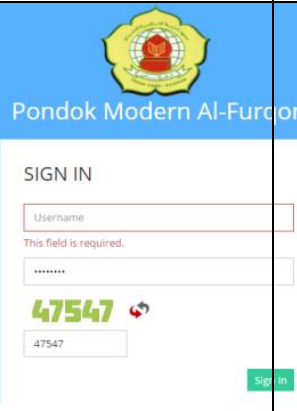 & Valid \\
\hline 4 & $\begin{array}{l}\text { Mengisikan salah satu data } \\
\text { dan captcha dengan benar } \\
\text { dan satu lagi salah, lalu } \\
\text { langsung klik tombol "sign } \\
\text { in". }\end{array}$ & 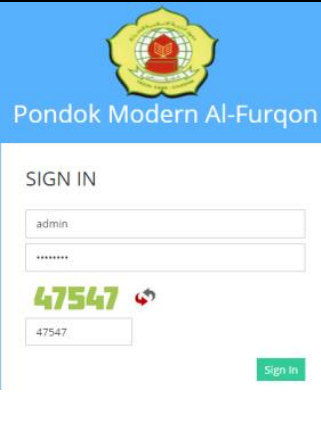 & $\begin{array}{l}\text { Sistem akan } \\
\text { menolak akses } \\
\text { sign in dan } \\
\text { menampilkan } \\
\text { pesan } \\
\text { “ Warning! Use } \\
\text { rname \& } \\
\text { password } \\
\text { invalid!". }\end{array}$ & $\begin{array}{l}\text { Pondok Modern Al-Furcol } \\
\text { SIGN IN } \\
\text { ading } \\
25535 \text { क }\end{array}$ & Valid \\
\hline
\end{tabular}




\begin{tabular}{|c|c|c|c|c|c|}
\hline 5 & $\begin{array}{l}\text { Mengisikan username, } \\
\text { password dengan benar } \\
\text { dan mengosongkan } \\
\text { captcha, lalu langsung klik } \\
\text { tombol "sign in". }\end{array}$ & 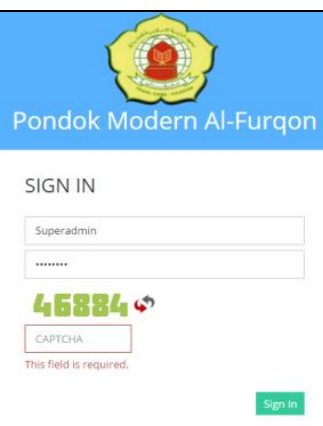 & $\begin{array}{c}\text { Sistem akan } \\
\text { menolak akses } \\
\text { sign in dan } \\
\text { menampilkan } \\
\text { pesan } \\
\text { "captcha, } \\
\text { tidak boleh } \\
\text { kosong". }\end{array}$ & 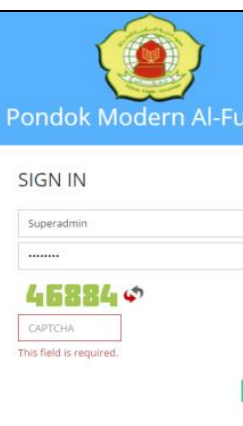 & Valid \\
\hline 6 & $\begin{array}{c}\text { Mengisikan username, } \\
\text { password dan captcha } \\
\text { dengan benar, lalu } \\
\text { langsung klik tombol "sign } \\
\text { in". }\end{array}$ & 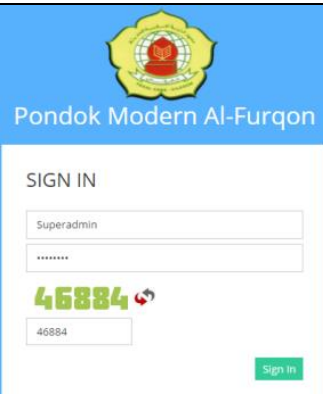 & $\begin{array}{c}\text { Sistem } \\
\text { menerima } \\
\text { akses sign in } \\
\text { dan masuk } \\
\text { pada menu } \\
\text { home. }\end{array}$ & Sesuai Harapan & Valid \\
\hline
\end{tabular}

\section{Kesimpulan}

Berikut kesimpulan perihal rumusan masalah mengenai Aplikasi Sistem Data Warehouse Pembelajaran Untuk Pondok Pesantren Al-Furqon adalah sebagai berikut:

1. Sistem pembelajaran yang berjalan saat ini pada Pondok Pesantren dapat dikatakan belum efektif. Hal tersebut dikarenakan sistem pembelajaran yang ada masih berjalan manual dan melibatkan banyak pihak sehingga memakan waktu lama dalam menyiapkan proses KBM. Karena belum didukung dengan media komputerisasi. Terlebih dalam hal pendataan yang masih manual. Guru-guru masih merasa nyaman dengan sistem manual sehingga tercipta santri yang berkarakter sama.

2. Untuk saat ini proses monitoring dilakukan dengan cara langsung menyaksikan proses KBM dan melihat data yang ada seperti : absen dan kualitias santri. Dengan sistem data warehouse yang diusulkan pimpinan mampu memonitoring history hasil pengajaran dan pendidikan yang dilakukan oleh guru terhadap santrinya melalui dashboard selaku pengontrol kualitas dari pada sistem pembelajaran. Agar tidak terjadi keterlambatan dalam melakukan peningkatan kualitas bagi para santri. Dengan para guru ikut membantu proses pendataan secara komputerisasi.

3. Menciptakan aplikasi sistem pendataan yang mampu membantu pondok pesantren dalam meningkatkan kualitas mutu pendidikan untuk para santri.

4. Dibandingkan dengan sistem proses yang berjalan dengan sistem usulan yakni manfaat yang didapatkan mampu untuk membantu pondok pesantren dalam menunjang pendataan yang lebih rapih dan tertata agar ketika data tersebut diperlukan mudah digunakan dan termonitoring dengan baik.

\section{Saran}

Saran yang dapat disampaikan oleh penulis adalah agar penelitian berikutnya bisa mengembangkan sistem ini lebih baik lagi, sehingga kekurangan yang ada bisa dilengkap atau diperbaiki. Saran yang dapat digunakan sebagai bahan pertimbangannya adalah sebagai berikut: 
1. Agar melakukan sosialisasi secara berkala perihal input nilai dari sistem manual para guru menuju data terkomputerisasi.

2. Perlu di implementasikan dari data offline ke data online agar lebih maksimal dalam kinerja sistem pendataannya.

3. Perlu pengembangan terhadap sistem menyesuaikan kebutuhan pengguna.

\section{DAFTAR PUSTAKA}

1. Adelia, d. J. (2011). Implementasi Customer Relationship Management (CRM) pada Sistem Reservasi Hotel berbasisi Website dan Desktop. Vol. 6, No. 2.

2. Akaichi, J. (2007). E-learning data warehouse maintenance system for collaborative learning availability resources optimization. International Journal of Education and Development using Information and Communication Technology, Vol. 3, Issue 3, pp. 16-29.

3. Alim, Y. (2012). Pengembangan Sistem Informasi Administrasi Pemeriksaan Pasien Di Instalasi Radiologi RSUD Kajen Dengan Unified Process. Semarang: Universitas Diponegoro.

4. Amelia, N. L. (2011). Analisis Dan Desain Data Warehouse Pada Perusahaan ASURANSI SYARIAH (STUDI KASUS : PT ASURANSI TAKAFUL UMUM). UIN Syarif Hidayatullah. Jakarta: repository.uinjkt.ac.id/dscape/handle/123456789/1766.

5. Arief, M. R. (2011). Pemrograman Web Dinamis Menggunakan PHP \& MySQL. Yogyakarta: Andi Offset.

6. Bassil, Y. (December 2012 ). A Data Warehouse Design for A Typical University Information System. Journal of Computer Science \& Research (JCSCR) - ISSN 2227328X, Vol. 1, No. 6, Pages. 12-17.

7. Diana Puspita Sari, D. I. (2014). Perancangan Sistem Penilaian Kinerja Karyawan Dan Pemberian Reward Menggunakan Analytical Hierarcy Process (AHP) Dan Fuzzy Synthetic Decision Approach (Studi Kasus : Karyawan Administrasi Universitas Diponegoro). Tangerang: Perguruan Tinggi Raharja.

8. Eka, P. Y. (2012). Aplikasi Penyewaan Ruangan PT. Simaeru Indonesia Raya Dengan Visual Basic 6.0. Depok. Universitas Gunadarma.

9. Elvioleta, Y. H. (2014). Perancangan Executive Information System Dalam Bidang Pelayanan Dan Perawatan Peswat Pada PT. GMF Aero Asia. Tangerang: Perguruan Tinggi Raharja.

10. Firdaus, I. (2014). Perancangan Executive Information System Dalam Bidang Penjualan Bahan Kimia Pada PT. RIDL Sejahtera. Tangerang: Perguruan Tinggi Raharja.

11. Guritno, S. S. (2011). Theory and Application of IT Research Metodologi Penelitian Teknologi Informasi. Yogyakarta.

12. Kadir, A. (2009). Dasar Perancangan Dan Implementasi Database Relasional. Yogyakarta: Andi Offset. 
13. Kosim, K. d. (2012). Perancangan Sistem. Yogyakarta: Andi Offset.

14. Kusuma. (2012). Aplikasi EIS (Executive Information System) Untuk Monitoring Transaksi Penjualan dan Pembelian. Tangerang: Perguruan Tinggi Raharja.

15. Madcoms. (2010). Kupas Tuntas Adobe Dreamweaver CS5 Dengan Pemrograman PHP \& MySQL. Yogyakarta: Andi Offset.

16. Mohammed F Al.Ajmi, S. K. (2013). Studying Data Mining and Data Warehousing with. (IJACSA) International Journal of Advanced Computer Science and Applications, Vol. 4, No.1.

17. Murad, D. F. (2013). Aplikasi Intelligence Website Untuk Penunjang Laporan PAUD Pada Himpaudi Kota Tangerang. Jurnal CCIT Perguruan Tinggi Raharja, Vol. 7, No.1.

18. Oktavian, D. P. (2010). Menjadi Programmer Jempolan Menggunakan PHP. Yogyakarta : Mediacom.

19. Osama E.Sheta, A. N. (June 2013). THE TECHNOLOGY OF USING A DATA WAREHOUSE TO SUPPORT DECISION-MAKING IN HEALTH CARE. International Journal of Database Management Systems ( IJDMS ), Vol.5, No.3.

20. Prasetio, A. (2012). Buku Pintar Pemrograman Web. Jakarta: Mediakita.

21. Radit. (2012). Perancangan Sistem Informasi. Yogyakarta: Andi Offset.

22. Rajni Jindal, S. T. ( February 2012). COMPARATIVE STUDY OF DATA WAREHOUSE. International Journal of Database Management Systems ( IJDMS ), Vol.4, No.1.

23. Rizky, S. (2011). Konsep Dasar Rekayasa Perangkat Lunak. Jakarta: Prestasi Pustaka.

24. Saputra, A. (2012). Kajian Kebutuhan Perangkat Lunak Untuk Pengembangan Sistem Informasi Dan Aplikasi Perangkat Lunak Buatan LAPAN Bandung. LAPAN.

25. Semiawan. (2010). Metode Penelitian Kualitatif. Jakarta: Grasindo.

26. Sidik, B. (2012). Pemrograman PHP. Bandung: informatika Bandung.

27. Simarmata, J. (2010). Rekayasa Web. Yogyakarta: Andi Offset.

28. Sulianta, F. D. (2010). Data Mining Meramalkan Bisnis Perusahaan. Jakarta: Elex Media Komputindo.

29. Sulindawati, d. M. (2010). Pengantar Analisa Perancangan "Sistem". Medan: STMIK Triguna Dharma.

30. Sutabri, T. (2012). Konsep Dasar Informasi. Yogyakarta: Andi Offset. 